Further evidence that the NRC is pursuing a more independent role than in the past is reflected by the increasing criticism-previously reserved for agencies such as the Occupational Safety and Health Administrationthat it is beginning to attract. Following the Seabrook decision, for example, Congressional representatives from New Hampshire called for legal action to reverse the ruling. They want to amend the Department of Energy and the NRC appropriations bills to assure construction of the plant.

It would be wrong to interpret last week's decision as indicating any major weakening in the administration's support of nuclear power. A number of other recent decisions--such as the Supreme Court's ruling that the PriceAnderson Act, which limits public liability for nuclear accidents to $\$ 500$ million, is not unconstitutional-have not helped the anti-nuclear cause.

Furthermore even minor victories can have their price. Last week, a number of staff members responsible for a Congressional report critical of the way that subsidies had distorted the apparent costs of nuclear power were fired from their posts.

Yet whether or not the NRC allows the Seabrook plant to go ahead, both sides now recognise that nuclear power has become a political issue, with many wider issues at stake than merely the well-being of a few shell-fish-or the adequacy with which government regulators fulfil their functions.

During the Seabrook demonstration, for example, Dr John Goffman, for many years a critic of the health dangers of nuclear energy, told the rally that "nuclear power is a symptom of a societal disease, the existence of privilege and power", a theme echoed in many other speeches.

Equally Governor Meldrim Thomson of New Hampshire has vowed to make Seabrook the rallying cry of a pronuclear, grass-roots movement; while a research fellow from Harvard University, criticising the protesters in a letter to the New York Times, complained that "to protest nuclear power is to strike at the marriage of science and capitalism".

As far as Seabrook itself is concerned, the ball now rests with EPA administrator Doug Costle, to whom environmentalists are pressing their case as he decides whether to give the planned cooling system the go-ahead.

As to the broader issues, with regulatory action now making a major economic impact on the nuclear power industry and the NRC taking an increasingly indcpendent line, the struggle between the supporters and the opponents of nuclear power seems destined to grow more intense.

\title{
Lack of basic energy research criticised
}

THE long-range security of US energy supplies has been jeopardised by the failure of the Department of Energy to give sufficient attention to longrange, fundamental research, according to a study commissioned by the Office of Science and Technology Policy.

The working party which carried out the study recommends that the balance between short-term and long-term needs in the department's research programmes "should receive early attention at the highest levels".

The working party also says there is a lack of balance in the research programmes carried out on federal funds by DoE laboratories, industry and the universities. To redress the balance, it suggests the budget for basic energy research in the universities should be increased. If necessary "funds should be diverted for this purpose from the development activities or even from other parts of the basic research programme".

The study was commissioned by $\mathrm{Dr}$ Frank Press, director of OSTP, in December 1977, and was carried out by a working party that included representatives of industry, government and the academic community, chaired by Dr S. J. Buchsbaum of the Bell Telephone Laboratories.

In a scaled-down version of comments which OSTP has itself made of federal research efforts in general, the working party criticises a preoccupation with near-term programmes and the consequent neglect of longer-term work. The dearth of research is especially evident, it says, in the solar and fossil fuel programmes.

Among the reasons for this imbalance, the working party lists a "misguided emphasis" on goals given to, or adopted by, the department which are clearly not yet attainable, and "excessive sensitivity" of some programme managers to political pressures.

As a mechanism to correct this situation, it is suggested that a committee be established under the

\section{Decline in scientific knowledge among 17-year-olds}

THE science scores of 17 -year-olds in US schools has dropped by $4.7 \%$ since 1969, according to a report released in Washington by the National Assessment of Education Progress.

A study of 9-year-olds and 13-yearolds showed less of a decline and an improvement in somc areas. For example, both 9 and 13-year-old students improved in tests in the biological sciences.

However in all three age groups scores in the physical sciences were chairmanship of the director of the Office of Energy Research, which should decide how to allocate funds to basic research.

Under this structure basic research would remain the responsibility of each assistant secretary, and a linkage therefore maintained between the research and its applications; however it would be less easy for a particular division to claim that it had increased its basic research activities merely by redefining existing programmes.

As far as federal laboratories with an applied research mission are concerned, the working party does not make any specific recommendation. But, picking its words carefully, it says that the "crispness of their missions has slowly eroded" in recent years, and that there exists a need for "greater quality control" over their basic research effort.

Turning to specific research needs and opportunities, the report lists a number of areas-including fossil fuels, fusion energy, and large scale solar power-in which it says longrange fundamental research should more frequently be given priority. As far as research in the environmental and life sciences related to energy matters is concerned, the report says it is essential for the DoE to avoid the "credibility problems" of its predecessor agencies. It therefore suggests that primary responsibility for basic research should be assumed by the director of the Office of Energy Research where the work is common to several energy technologies, and that the Assistant Secretary for the Environment should provide support for basic research relevant to environmental concerns in the technology area.

Although the report has no official status, it is said to have been well received both by Dr Press, and Energy Secretary Dr James Schlesinger. Its reception by both fiscal conservatives, and those Congressmen concerned with specific development projects, however, is less predictable.

David Dickson

lower in the 1976-77 school year than in either of the previous two examiniation periods in 1969-70 and 1972-73.

The declining performances of 17 year-olds seems closely related to the fact that the number of students taking science courses in high school has dropped-from about $18 \%$ in the late $1960 \mathrm{~s}$, when attention on space exploration heightened interest, to less than 10 per cent now. 